\title{
WATER ON VENUS?
}

W. F. LIBBY and P. CORNEIL

Dept. of Chemistry and Institute of Geophysics and Planetary Physics, University of California, Los Angeles, Calif. U.S.A.

\begin{abstract}
It is proposed that Venus may have polar seas which are acidic and thus cannot precipitate calcium carbonate. This leaves the carbon dioxide in the atmosphere. The argument is that the great equatorial land masses always have been too hot for liquid water and thus could not be weathered to give the sea salts necessary to form the precipitate. The action of steam on rocks is to liberate acids which are volatile and would dissolve in the polar seas. The volcanic vapors issuing in the early times consisting mainly of water and carbon dioxide would have begun polar seas at once since the expected equatorial (black body) surface temperature of the bare planet is too high ( $464 \mathrm{~K})$ due to proximity of the sun. The accumulation of carbon dioxide in the atmosphere would have ensured the continued increase of the temperature due to the greenhouse effect. On earth, on the contrary, condensation over most of the planetary surface probably was possible from the beginning. Liquid water, ice-weathering, and river transport of salts to the seas all probably occurred from the beginning.

As the pressure at the surface probably approximates 100 atm (Venera 5 and 6) we can expect the polar seas to be below the boiling point although possibly hot. An isothermal layer of some thickness is naturally established over liquid water heated by infrared from above. Evaporation and condensation to form rain constitutes an efficient heat transport mechanism. Such a layer naturally would move toward lower latitude carrying moisture which then will rise and eventually move poleward in the high atmosphere causing rain and possibly the planet wide cloud cover. The atmosphere containing volatiles such as hydrochloric and hydrofluoric and sulfurous and sulfuric acids as well as carbon dioxide will form clouds which might be expected to consist of concentrated acid solutions. The main rain over the poles probably falls from altitudes well below the cloud top seen from earth. It is possible that the Venus clouds seen from earth are non aqueous just as our stratosphere carries dust clouds apparently of ammonium sulfate. At the moment it is very difficult to decide between these alternatives.

In the more polar regions the seas might conceivably be as cool as $50^{\circ} \mathrm{C}$.
\end{abstract}

\section{Introduction}

It has been known for quite some time that the atmosphere of Venus has water vapor. Photographs of the spectrum of Venus in the region of the $8200 \AA$ water vapor band have indicated the presence of water (Dollfus, 1963; Bottema et al., 1964; Belton and Hunten, 1966; Spinrad and Shawl, 1966; Owen, 1967). Owen (1967) estimates a maximum of about $16 \mu \mathrm{g}$ of ppt $\mathrm{H}_{2} \mathrm{O}$ per $\mathrm{cm}^{2}$. Convincing proof for the existence of water vapor has, however, come from the measurements of the space probes, Venera 4, 5, 6 and Mariner V, in the atmosphere of Venus. Venera 4 indicated 1 to $8 \mathrm{mg} \mathrm{liter}^{-1}$ of water (Vinogradov et al., 1968) whereas Venera 5 and 6 ('Venera 5 and 6', 1969) gave 4 to 11 at 0.6 atm total pressure and $25^{\circ} \mathrm{C}$. Observations of Mariner $\mathrm{V}$ also indicated small amounts.

Based on these small amounts of water, Sagan (1967) and Rasool (1968) have suggested that water may have been continuously lost from Venus at approximately the same rate as it is outgassed from the interior. They suggest that the water is dissociated by solar ultraviolet radiations of $\lambda<1800 \AA$ in the stratosphere at the rate of $10^{11}-10^{12}$ mole $\mathrm{cm}^{-2} \mathrm{sec}^{-1}$ and that the hydrogen produced by dissociation 
diffuses rapidly upwards with a velocity of $110 \mathrm{~cm} \mathrm{sec}^{-1}$ at the $100 \mathrm{~km}$ level and at much greater speeds at higher altitudes and escapes from the planet with an escaping flux of about $10^{11}$ mole $\mathrm{cm}^{-2} \mathrm{sec}^{-1}$ at the exosphere level. The atomic oxygen released in the photodissociation process is rapidly used up by oxidation.

This proposal, though applicable for the loss of some water from Venus, probably cannot account for the loss of water equivalent to the amount present as excess volatile on earth (Rubey, 1964). This has already been pointed out (Jastrow, 1968). In this paper we wish to re-examine the possibility of the existence of large quantities of condensed water in the relatively cooler regions of the planet. The principle of chemical similarity between sister planets induces us to consider such a possibility.

Libby (1968) proposed earlier that extensive ice caps might be present in the polar regions of Venus. At the time this model was proposed the high temperatures and pressures now known for the planet were not as firmly established and based on the then available data of $270{ }^{\circ} \mathrm{C}$ and 20 atm (from original reports of Venera 4) for the equator, it appeared to be possible that the poles could be cool enough to sustain ice caps as on earth. However, the present data from Venera 5 and 6 now on hand confirm the Mariner V and the microwave conclusions of the American School (see e.g., Jastrow, 1968) that the surface temperatures and pressures in the equatorial regions may well be about $800 \mathrm{~K}$ and 75 to $100 \mathrm{~atm}$. Assuming a mean temperature gradient of about $3 \mathrm{~K} /$ degree latitude (Fabian et al., 1968), a polar temperature of about $500 \mathrm{~K}$ might be possible. This temperature agrees well with the temperature at the poles derived from radioastronomical data (Clark and Kuzmin, 1965) $-\geqslant 420 \mathrm{~K}$; Pollack and Sagan (1965) $-470 \pm 95 \mathrm{~K}$ ) and from theoretical calculations (Fabian et al. (1968) $\sim 500 \mathrm{~K}$ ). Even at the originally reported equatorial temperatures the difficulty of preserving the ice caps at the poles was considerable and led to serious questions (Weertman, 1968; Owen, 1968; Bussinger and Holton, 1968). The higher temperatures at the poles now make the ice caps untenable, but appear to us not to necessitate the complete elimination of water. The boiling point of water at 100 atm is $314{ }^{\circ} \mathrm{C}$ $(586 \mathrm{~K})$.

\section{The Concept of Polar Seas: Their Acidity and Failure to Precipitate $\mathrm{CO}_{2}$}

A careful examination of the factors that can influence the existence of liquid water on Venus indicates that indeed oceans of water may be preserved at Venus' poles, and since it is logical that the poles were relatively cooler than the equator in the early history of the planet liquid water might have condensed at the poles from the very beginning and have existed throughout the life span of the planet.

If we assume that the water on Venus is equal in amount to the water on earth the polar seas would have to be about $9 \mathrm{~km}$ deep and extend down to $55^{\circ}$ latitudes. However, some water might have been lost from the planet through photodissociation, as suggested by Sagan and Rasool. Also Fricker and Reynolds (1968) conclude that more water may have stayed in the Venus crust than on earth because the temperature being higher would raise the $\mathrm{H}_{2} \mathrm{O}$ partial pressure in the Venus atmosphere higher and keep the water in rocks higher. Such considerations would reduce the total amount of 
water in the oceans to a certain extent and make the polar seas narrower and shallower, but in our judgment there seems to be little possibility of avoiding oceans unless the planets are truly dissimilar chemically.

We assume that the polar seas on Venus would be nearly as old as the oceans on earth and since the oceans on earth are found to be at least 3 billion years old, oceans might have been formed at the poles of Venus about 3 billion years ago. The primitive oceans, developed by the condensation of accumulated moisture in the atmosphere, would have dissolved all the other soluble volatile gases, like $\mathrm{HCl}, \mathrm{HF}, \mathrm{SO}_{3}, \mathrm{CO}_{2}$, $\mathrm{NH}_{3}$, etc. and would have been highly acidic. Unfortunately it is not possible to estimate precisely the amounts of water and of these dissolved gases developed 3 billion years ago. However, since the acidic volatiles predominate, the primitive oceans probably would have been highly acidic. Introduction of all the chlorine present on earth as excess volatile into the Venus' polar seas in the form of $\mathrm{HCl}$, would yield a concentration of about 0.5 mole/l. Sulphur probably would have been oxidized to $\mathrm{SO}_{3}$ and $\mathrm{H}_{2} \mathrm{SO}_{4}$ in the Venus' atmosphere (Corneil and Heber, 1968; Corneil and Budgor, 1969) to give amount equivalent to about $0.05 \mathrm{~mole} / \mathrm{1}^{-1}$. In addition to these two major acidic gases, $\mathrm{CO}_{2}$ dissolves to the extent of about $0.5 \mathrm{~mole} / \mathrm{1}^{-1}$ at an atmospheric pressure of 80 bar and with water temperature of about $200{ }^{\circ} \mathrm{C}$. This acidity would appear to explain the failure of the $\mathrm{CO}_{2}$ to precipitate $\mathrm{CaCO}_{3}$ as happened on earth.

Our studies (Raman et al., 1969) of the corrosion of igneous rocks and minerals by such highly acidic solutions show that considerable attack of the sea bed would occur introducing metal cations; however the Venus oceans would appear to remain highly acidic even though substantial extraction occurs. Harvey (1945) estimates that when $\mathrm{CaCO}_{3}$ precipitates, the concentration of $\mathrm{Ca}^{2+}$ and $\left[\mathrm{CO}_{3}^{2-}\right]$ would be 0.15 and $8 \times 10^{-6}$ mole $/ 1^{-1}$ respectively at a $\mathrm{pH}$ of 5.1. Below this level of $\mathrm{pH}$ the carbonate precipitation does not occur. Since the $\mathrm{pH}$ of the sea water on Venus probably would not have risen to this level, no carbonates would have precipitated, and $\mathrm{CO}_{2}$ is preserved in the atmosphere.

It is obvious that although the temperature of the water probably will be well below the boiling point in the polar regions some evaporation will occur from the surface and some of the water vapor, as described below, would be carried to lower latitudes by itinerant winds. However, since the temperature on the equatorial part of Venus apparently is much higher than the boiling point of water at the 100 atm pressure $\left(314{ }^{\circ} \mathrm{C}\right)$ it cannot rain in these hotter regions. As a result the weathering of planetary rocks cannot take place on Venus and no rivers can flow and so no salts will be carried into the seas. This makes the sea bed the only source for salts and limits the accumulation of basic constituents in the sea water and the precipitation of carbonates probably would not occur. Under these circumstances the salt content of the seas may be fairly low, as compared to the sea water on earth.

\section{Preservation of Polar Seas: Temperatures}

Can such polar seas be preserved in the hot $\mathrm{CO}_{2}$ atmosphere? We have studied the evaporation characteristics of similar acidic aqueous solutions in the presence of $\mathrm{CO}_{2}$ 
at high pressure (Raman et al., 1969). The experimental results are interesting and favor the preservation of Venus' polar seas. We find that with increased pressures of $\mathrm{CO}_{2}$ increased amounts of thermal energy are required to heat the water. Only the sunlight can penetrate and heat the water at depths below the very surface, for the hot equatorial air descending over the polar seas radiates infrared, which is completely absorbed by the underlying moisture laden atmosphere and the top water layers. Our experiments have confirmed that the main deep water cannot be heated by this infrared and that only the visible sunlight and, of course, the outward flowing heat from the ocean floor can reach it. An approximately isothermal layer is established in the air over the water surface the thickness of which can only be estimated but which may be very substantial. At the top of the layer rain forms and the heat of condensation is released. This constitutes a kind of nearly isothermal heat transport device. In this way we estimate that much of the polar seas area may be as cool as $100{ }^{\circ} \mathrm{C}(373 \mathrm{~K})$.

\section{Wind Pattern at the Poles}

Mintz (1961) found evidence for atmospheric circulation and proposed a model for it. In his model, however, no pattern is suggested for the winds at the poles. Goody and Robinson (1966) have also discussed the wind patterns. Their results indicate that winds are prevalent on Venus. The data of Venera 4 also indicated a steady vertical wind of $\leqslant 0.5 \mathrm{~m} \mathrm{sec}^{-1}$ during its descent into the atmosphere of Venus (Avduevsky et al., 1968). We suggest a wind pattern at the poles, which would be compatible with the findings of other investigators.

Horizontal winds just above the surface of the polar ocean would be directed toward lower latitudes and these winds would carry moisture from the evaporating ocean surface and would be relatively cool. At a later stage the relatively cool horizontal winds would interact with the hotter winds at lower latitudes and vertical tropical winds would be set up, mixing the moisture upward to higher altitudes at relatively high speeds. We suggest that such vertical winds would prevail at around $50^{\circ}$ latitude level. At the higher altitudes the winds would blow toward the poles where the moisture content would increase steadily until the relative humidity exceeded a certain critical value, when condensation would occur and clouds would form. These clouds would be at much lower altitudes as compared to the clouds observed from earth (Dollfus, 1955). Rain then would bring the water back to the oceans and deplete the moisture content of the upper altitudes above the poles.

Evaporation of water from the ocean and back condensation and rain result in efficient removal of heat brought to the surface of water by the itinerant winds. In other words, the process may be similar to an efficient 'heat pipe'. The heat liberated in the condensation process heats the upper zone and is radiated back into space ultimately. The wind conditions might vary with time, but apparently never could lead to drying of the oceans. The ocean protects itself by evaporation and formation of a cloud.

The suggested wind pattern does not allow much moisture to accumulate in the major portions of the atmosphere of the planet, especially near the equator, where 
observations have been made of the water content. The mixing vertical winds at the $50^{\circ}$ latitude level may carry some water and other acidic volatiles aloft to form the observed cloud cover.

The suggested model would facilitate the greenhouse effect. (Pollack, 1968). We feel that a 'closed system' for water such as the one proposed to exist at the poles, retains most of the water in a relatively narrow region and prevents the detection of water in major amounts in the cool upper atmosphere through earth based observations.

\section{The Planetary Clouds}

As stated previously some of the moisture will move into the equatorial belt and not all may be efficiently returned poleward to give low level rains. Some of this may eventually reach the greatest altitudes and condense to form acid laden droplets. We suggest that these may constitute the clouds shrouding the planet as a whole.

It is possible, however, that the great cloud cover consists mainly of a non-aqueous system as suggested by Kuiper since there is so little water in the very high layers visible from the earth (about $55 \mathrm{~km}$ at $10^{\circ} \mathrm{C} / \mathrm{km}$ and with the observed temperature of $-30{ }^{\circ} \mathrm{C}$ ). In our own stratosphere the moisture content is as low as that of Venus and we have clouds of solid particles said to be in part ammonium and metallic sulfates (Junge, 1963). The Venus clouds may have a similar constitution and at some lower level over the polar regions only true water clouds may occur. However, Venera 5 and 6 report 4 to $11 \mathrm{mg}$ of water per liter at $0.6 \mathrm{~atm}$ and $25^{\circ} \mathrm{C}$. Since $23 \mathrm{mg}$ would correspond to saturation, such air would have to be cooled to form droplets, but this would appear to be possible at a few kilometers higher altitudes. So it is not clear whether the observed clouds are aqueous or not even if there is abundant water on the planetary surface, as seems to us to be likely.

\section{Acknowledgment}

This research was supported in part by the United States Air Force Office of Scientific Research, Grant No. AFOSR 1255-67, and the National Aeronautics and Space Admin., Grant No. NSG 05-007-003.

\section{References}

Avduevsky, V. S., Marov, M. Ya., and Rozhdestvensky, M. K.: 1968, 'Model of the Atmosphere of the Planet Venus', J. Atmospheric Sci. 25, 537-545.

Belton, M. J. and Hunten, D. M.: 1966, 'Water Vapor in the Atmosphere of Venus', Astrophys. J. 146, 307.

Berkner, L. V. and Marshall, L. C.: 1964, 'The History and Growth of Oxygen in the Earth's Atmosphere', in The Origin and Evolution of Atmospheres and Oceans (ed. by P. J. Bracazio and A. G. W. Cameron), John Wiley and Sons, Inc., New York.

Bottema, M., Plummer, W., Strong, J., and Zander, R.: 1964, 'Composition of the Clouds of Venus', Astrophys. J. 140, 1640-1641.

Bottema, M., Plummer, W., and Strong, J.: 1965, 'A Quantitative Measurement of Water Vapor in the Atmosphere of Venus', Ann. Astrophys. 28, 225-228.

Clark, B. G. and Kuzmin, A. D.: 1965, 'The Measurement of the Polarization and Brightness Distribution of Venus at $10.6 \mathrm{~cm}$ Wave Length', Astrophys. J. 142, 23. 
Connes, P., Connes, J., Benedict, W. S., and Kaplan, L. D.: 1967, 'Traces of $\mathrm{HCl}$ and HF in the Atmosphere of Venus', Astrophys. J. 147, 1230-1237.

Corneil, P. and Heber, D.: 1968, 'Sulphuric Acid and the Nature of the Lower Atmosphere of Venus', unpublished report, Chemistry Department, UCLA.

Corneil, P. and Budgor, A.: 1969, This report calculates that sulfur in a $\mathrm{CO}_{2}$ atmosphere is found as $\mathrm{H}_{2} \mathrm{SO}_{4}+\mathrm{SO}_{3}$ at $590 \mathrm{~K}$.

Dollfus, A.: 1955, 'Etude visuelle et photographique de l'atmosphere de Venus', L'Astronomie 69, 413-425.

Dollfus, A.: 1964, 'Mesure de la vapeur d'eau dans les atmospheres de Mars et de Venus', Mem. Soc. Roy. Sci., Liege, Serie 5, 9, 392-395.

Fabian, P. and Libby, W. F.: 1969, 'Ozone in the Atmosphere of Venus and Its Contribution to the Heat Budget', $Z$. Geophys. 35, 1.

Fabian, P., Sasamori, T., and Kasahara, A.: 1958, 'Radiative-Convective Equilibrium Temperature Calculation of the Venus Atmosphere', unpublished report, National Center for Atmospheric Research, Boulder, Colo.

Fricker, P. E. and Reynolds, R. I.: 1968, Icarus 9, 221.

Goody, R. M. and Robinson, A. R.: 1966, 'A Discussion of the Deep Circulation of the Atmosphere of Venus', Astrophys. J. 146, 339-355.

Harvey, H. W.: 1945, Recent Advances in the Chemistry and Biology of Sea Water, Cambridge Univ. Press, pp. 61-68.

Jastrow, R.: 1968, 'The Planet Venus', Science 160, 1403-1410.

Junge, C. E.: 1963, Air Chemistry and Radioactivity, Academic Press.

Kliore, A. and Cain, D. L.: 1968, 'Mariner 5 and the Radius of Venus', J. Atmospheric Sci. 25, 549-554.

Kuiper, G.: 1969, private communication.

Libby, W. F.: 1968, 'Ice Caps on Venus', Science 159, 1097; 160, 1474; 161, 916.

Mintz, Y.: 1961, 'Temperature and Calculation of the Venus Atmosphere', Planetary Space Sci. 5, 141-152.

Mueller, R. F.: 1968, 'Sources of $\mathrm{HCl}$ and $\mathrm{HF}$ in the Atmosphere of Venus', Nature 220, 55.

Ohring, G. and Mariano, J.: 1964, 'The Effect of Cloudiness on the Greenhouse Model of the Venus Atmosphere', J. Geophys. Res. 69, 165-175.

Owen, T.: 1967, 'Water Vapor on Venus - A Dissent and a Clarification', Astrophys. J. Letters 150, L121.

Owen, T., Bussinger, J. A. and Holton, J. R.: 1968, 'Ice on Venus: Can It Exist ?' Science 161, 916.

Pollack, J. B. and Sagan, C.: 1965, 'The Microwave Phase Effect of Venus', Icarus 4, 62-103.

Pollack, J. B.: 1969, 'A Non-Gray $\mathrm{CO}_{2}-\mathrm{H}_{2} \mathrm{O}$ Greenhouse Model of Venus, Icarus 10, 314.

Raman, A. and Johnson, R. G.: 1969, 'Corrosion of Igneous Rocks and Minerals by Aqueous Acidic Solutions in the Presence of $\mathrm{CO}_{2}$ ', unpublished report, Department of Chemistry, UCLA.

Raman, A. and Nemes, P.: 1969, 'Evaporation of Water and Aqueous, Acidic Solutions in the Presence of $\mathrm{CO}_{2}$ at High Pressures', unpublished report, Department of Chemistry, UCI_A.

Raman, R.: 1969, ' $\mathrm{pH}$ Variations in Carbonate-Acid Reactions in the Presence of $\mathrm{CO}_{2}$ at $\mathrm{High}$ Pressures', unpublished report, Department of Chemistry, UCLA.

Rasool, S. I.: 1968, 'Loss of Water from Venus', J. Atmospheric Sci. 25, 663.

Rubey, W. W.: 1964, 'Geologic History of Sea Water', in The Origin and Evolution of Atmospheres and Oceans (ed. by P. J. Bracazio and A. G. W. Cameron), John Wiley and Sons, Inc., New York, pp. 1-63.

Sagan, C.: 1967, 'Origins of Atmospheres, of Earth and Planets', International Dictionary of Geophysics, Oxford, Pergamon Press, pp. 97-106.

Spinrad, H. and Shawl, S. J.: 1966, 'Water Vapor on Venus - A Confirmation', Astrophys. J. 146, 328.

'Venera 5 and 6' Pravda No. 155 (18568) of 4 June 1969, Moscow.

Vinogradov, A. P., Surkov, U. A., and Florensky, C. P.: 1968, 'The Chemical Composition of the Venus Atmosphere Based on the Data of the Interplanetary Station, Venera 4', J. Atmospheric Sci. 25, 535-536.

Wertman, J. W.: 1968, 'Venus: Ice Sheets', Science 160, 1673. 


\section{Discussion}

Morrison: The most recent Greenbank interferometry of Venus by Sinclair and coworkers shows no sign of cold poles. How does this affect your hypothesis?

Libby: If there is no special absorber in the equatorial region, we'll have to reconsider.

Golitsyn: The similarity theory also shows a very small temperature difference between equator and pole.

Sagan: I just want to support Dr. Morrison's remark. The early interferometric data which implied cold poles and the early phase data which implied a cold antisolar point have both been supplemented by more recent data suggesting a much more isothermal surface. 